\title{
The Market For Follow-On Biologics: How Will It Evolve?
}

The market for biologically derived treatments differs in important ways from the market for chemically derived drugs.

\section{by Henry Grabowski, lain Cockburn, and Genia Long}

ABSTRACT: With spending on biologics rising and patent expiry approaching for several blockbuster biologics, Congress and the Food and Drug Administration are considering creating a clear pathway for so-called follow-on biologics. Differences between drugs and biologics will affect market outcomes in various ways. Conservative budget impacts are appropriate in the short run because fewer competitors will enter, and average prices will drop less than was the case following the Hatch-Waxman Act. Over the long term, intellectual property provisions will be important considerations for policymakers designing a pathway for follow-on biologics that balances price competition and innovation incentives. [Health Affairs 25, no. 5 (2006): 1291-1301; 10.1377/hlthaff.25.5.1291]

$\mathrm{B}$ IOLOGICS REPRESENT A SIZABLE SEgMENT of the U.S. drug industry, with sales expected to exceed $\$ 60$ billion by 2010. ${ }^{1}$ Because these products are growing at twice the rate of prescription drugs (2004), health plans, employers, and government insurers have concerns about their potential financial impact, while patients are concerned about continued access to potentially beneficial therapies. With patents for a number of blockbuster biologics (medical treatments derived from living organisms) expiring in the next several years, Congress and the Food and Drug Administration (FDA) are under pressure to enable the expedited approval of so-called follow-on biologics (also referred to as biogenerics or biosimilars), thus paving the way for the development of a robust U.S. follow-on biologics industry, following the lead of the Hatch-Waxman Act for generic drugs.

Proponents of an approach similar to that embodied in Hatch-Waxman make several assumptions about its economic impact: First, there will be many entrants, and competition will be based primarily on price; second, prices will drop substantially, and consumers will have better access to biologics; and third, incentives for innovation will not weaken. However, the market for follow-on biologics might develop differently from that for generic drugs for a number of reasons.

Henry Grabowski (grabow@econ.duke.edu) is a professor of economics at Duke University in Durham, North Carolina. Iain Cockburn is a professor of finance and economics in the School of Management, Boston University, in Boston, Massachusetts. Genia Long is a vice president of the Analysis Group in Boston.

HEALTH AFFAIRS Volume 25, Number 5 
We examine important differences between biologics and drugs that could affect market outcomes. We then consider how the market is likely to evolve, conditional on the regulatory environment, technological and marketing barriers to entry, and market acceptance. We also point out some important open policy questions and identify priority areas for further empirical investigation.

\section{The Hatch-Waxman Act And Biologics}

The Drug Price Competition and Patent Term Restoration Act of 1984 (often referred to as the Hatch-Waxman Act) established the Abbreviated New Drug Application (ANDA) process for generic drug approval. In reviewing ANDAs, the FDA relies on a prior finding of safety and efficacy for a referenced pioneer drug, with a generic applicant having only to demonstrate bioequivalence between its product and the referenced drug. ${ }^{2}$ Prior to 1984 , generic drugs were subject to the same approval requirements as innovator drugs.

Although the Hatch-Waxman Act provides a clear path for generic drug market entry, it generally does not apply to biologics. Drugs are regulated by the federal Food, Drug, and Cosmetic Act (FD\& $\&$ Act), and biologics are generally regulated under the Public Health Service Act (PHS Act), which has no equivalent provision to the ANDA allowing the expedited approval of generic versions of approved, onmarket products. Some early biologics, such as human growth hormone (hGH), insulin, and conjugated estrogens, were approved as drugs under the FD\&C Act. ANDAs could be approved for these products, subject to FDA resolution of the scientific and other issues involved. ${ }^{3}$ However, congressional action will be required before follow-on versions of biologic products regulated under the PHS Act can be approved by the FDA. Congress and the FDA are considering various scientific and legal issues surrounding follow-on biologics, to define a regulatory process for them.

Biologics are typically more complex molecules than chemical drugs; they are not manufactured through chemical synthesis but instead are produced through biological processes involving manipulation of genetic material and large-scale cultures of living mammalian, microbial, or yeast cells. Biologics made in different cell lines or manufacturing plants might behave differently as medicines and exhibit unexpected adverse events in vivo. These basic differences in turn lead to important differences in the economics of discovery, development, manufacturing, and distribution for drugs and biologics. Consequently, this could lead to different economic outcomes in terms of average prices, number of competitors, returns on spending for research and development (R\&D), and other market measures.

\section{Economic Analyses Of Pharmaceuticals And Biologics}

- Innovators' R\&D costs. A number of studies have investigated the average cost to discover and develop a new drug. Joseph DiMasi and colleagues estimate R\&D costs at $\$ 403$ million per new drug in an oft-cited study. ${ }^{4}$ When capitalized to 
the point of marketing approval at a real discount rate of 11 percent, the total preapproval cost is $\$ 802$ million (in 2000 dollars). ${ }^{5}$ Although the sample of biologics in this study was small, the limited data suggested that development costs were similar for biologics and drugs.

A recent analysis by DiMasi and Henry Grabowski examined the R\&D costs for a data set of recombinant proteins and monoclonal antibodies. ${ }^{6}$ The authors assembled drug-specific data on R\&D costs by phase of development for a sample of seventeen biologic products drawn from these two categories. These data were integrated with a larger database on transition probabilities and development times for new biologics. The authors found that the R\&D costs for new biologics are comparable in magnitude to DiMasi and colleagues' previous estimates for drugs (after adjustments were made for the different time periods covered by the two studies). ${ }^{7}$ However, they also found that the underlying R\&D cost components differed substantially between new biological entities and drugs. Specifically, biologics realized higher probabilities of clinical success (30 percent compared with 21.5 percent for new drugs) but also experienced longer mean clinical development times (ninety-eight versus ninety months). These findings are consistent with earlier analyses of these parameters. ${ }^{8}$

The DiMasi-Grabowski study also suggests that the development of biologics entails higher manufacturing process costs than is true for drugs. This reflects the need to resolve novel manufacturing challenges at the R\&D stage for products developed through fermentation or fragile mammalian cell cultures. By contrast, manufacturing process issues in $\mathrm{R} \& \mathrm{D}$ are more straightforward for new chemical drugs. Process specifications and know-how will be important for the FDA to consider from both a regulatory and an intellectual property (IP) perspective in developing guidelines for follow-on biologics.

- Imitators' R\&D costs. It remains to be seen what the regulatory requirements will be for follow-on biologics. Given that biologics made with different cell lines or manufacturing facilities might exhibit different efficacy and safety characteristics, it is likely that some clinical trial data will be required before a follow-on biologic is approved. New follow-on entrants might not have to repeat all of the original sponsor's clinical steps or incur the costs associated with large Phase III clinical trials. However, even relatively small trials of biologics in a few hundred patients are likely to cost tens of millions of dollars and take several years to complete. In the case of European approvals, some generic companies' estimates suggest that a plausible range could be $\$ 10-\$ 40$ million. ${ }^{9}$ The exact amount is likely to depend on how wellcharacterized the molecule is and on other scientific and technological factors. This contrasts with the $\$ 1-\$ 2$ million cost and approximately two years necessary to demonstrate bioequivalence for generic drugs. ${ }^{10}$

While Congress and the FDA consider the legal and scientific framework for follow-on biologics, branded competition for biopharmaceuticals such as hGH and recombinant insulin has emerged using the New Drug Application (NDA) 
regulatory pathway. In the case of hGH, six manufacturers are approved for marketing in the United States. ${ }^{1 l}$ These manufacturers received FDA approval under separate NDAs by conducting their own comprehensive Phase III studies to demonstrate efficacy and safety. The products are not rated as bioequivalent by the FDA and cannot be substituted for each other, although managed care plans might view them as undifferentiated. Competition in hGH is also multidimensional: Products are marketed under separate brand names and compete on price, promotion, and product differentiation (for example, with different delivery systems such as pen dispensers). Follow-on biologics might retain some elements of this competition, as discussed further below.

- Manufacturing cost and risk. The required capital investment in property, plant, and equipment and the costs of manufacturing are also likely to be higher for follow-on biologics than for generic drugs. Cell culture facilities require sizable capital and labor investment, taking, on average, three to five years to construct and costing \$250-\$450 million. Investment in manufacturing plants must often be made before drugs enter clinical testing. Cost of materials is also high; in 2002 these materials cost twenty to one hundred times more than those used for drugs. ${ }^{12}$

- Market size. As in the market for drugs, the sales distribution of biologics is highly skewed, with relatively few compounds accounting for a disproportionate share of sales and profits. Of thirty new biologics introduced from 1982 to 1994, onefifth accounted for roughly 70 percent of total 2002 sales. $^{13}$ Biologics in the top quintile or decile of sales will attract the most interest from follow-on manufacturers. Several studies have established that the number of entrants for generic drugs is strongly related to the size of the brand-name product's sales prior to entry. ${ }^{14}$

It is also relevant that many biologics have been "niche drugs" targeting rare conditions and small numbers of patients. As a result, during 1983-2001, biotech firms accounted for two-thirds of the research on orphan drugs-whose estimated maximum U.S. markets were no more than 200,000 patients-although they represented fewer than half of FDA approvals. ${ }^{15}$ Among these products, only those with sizable revenues would be expected to attract generic competition.

- Product margins. Average net income as a percentage of gross revenue and gross margin percentage for mature biotech companies approximate those of major pharmaceutical manufacturers, although the distribution of expenses differs somewhat, with a higher percentage of gross revenues to $R \& D$ and lower percentage to sales, marketing, and administrative costs. ${ }^{16}$ However, there are few such companies. The universe of biotech firms is populated with development-stage companies. Most are not profitable, and the variance of such financial statistics is greater than for the pharmaceutical industry. The market structures of the two industries are therefore very different.

Distribution structure and supply-chain incentives. Markets for biologics and drugs also differ in the structures of their distribution systems and in the economic incentives for participants in the value chain. Most drugs are oral agents dis- 


\section{"Changes in regulation could lead to hard-to-predict long-term effects on capital investment in the biotech industry."}

tributed through retail and mail-order pharmacies. Strong financial incentives and systems favor rapid generic penetration. Managed care plans adjudicate and budget for these claims as pharmacy benefits. They have implemented strong formulary management systems, including preferred formulary status and lower copayments for or mandatory use of generics. Financial incentives for drug retailers also favor rapid generic drug substitution, because they often earn higher gross profit margins on generic drugs than on brand-name drugs. ${ }^{17}$ Medicare Part D drug plans will extend these incentives for generic drug penetration with formulary designs that are at least as aggressive as those in their current commercial lines of business.

In contrast, biologics include both injected or transfused agents delivered in a physician's office, clinic, or hospital and self-injectible products dispensed through pharmacies. Medicare reimbursement for infusions delivered in clinics and physicians' offices historically has been maintained at artificially low levels, resulting in the need for cross-subsidies between these rates and the spread between average wholesale price (AWP) and actual acquisition cost. This has been addressed somewhat by increasing procedure reimbursement, decreasing infusedagent reimbursement with the shift in January 2005 from AWP- to average sales price (ASP)-based reimbursement, and the recent implementation of the voluntary competitive acquisition program (CAP). The long-term impact on incentives for the substitution of lower-cost products is unknown. ${ }^{18}$

Because many biologic therapies are designed to treat cancer and other lifethreatening diseases and might not have close substitutes, managed care organizations in the past have been reluctant to restrict access or to pursue aggressive cost or utilization control processes. Biologics often have been managed within plans as medical benefits, which have been less subject to centralized formulary controls than pharmacy benefits have. This is changing, particularly in indications where there is a choice between multiple brand-name biologics, and tiered formularies reflect considerations of net cost after manufacturer rebates. ${ }^{19}$ Increasingly, a fourth tier, which includes expensive biologic therapies and coinsurance rather than copayment, is emerging. These institutional practices will likely accelerate with the introduction of follow-on biologics, but the speed of change will depend on how rapidly concerns about safety can be satisfactorily addressed.

\section{Intellectual Property Considerations}

IP provisions in the Hatch-Waxman Act have led to evolving levels of strategic behavior on the part of both generic and brand-name pharmaceutical firms. These provisions also have been the source of much litigation. Specifically, HatchWaxman provided an inducement to patent challenges by rewarding the first suc- 
cessful generic challengers with 180-day exclusivity. As a consequence, generic firms now follow "prospecting" business models involving patent suits, and virtually all profitable pharmaceuticals face patent challenges after their first five years of market life. ${ }^{20}$ Generic entry based on an ANDA can occur after the five-year data exclusivity period expires, but subject to a thirty-month stay on entry while courts adjudicate patent validity and infringement. Brand-name firms also have used various IP provisions to forestall entry, such as multiple stays on entry. Congress addressed this behavior in the Medicare Prescription Drug, Improvement, and Modernization Act (MMA) of 2003. ${ }^{21}$

IP is a critical intangible asset for biotech and pharmaceutical firms. ${ }^{22}$ Given the entrepreneurial nature of the biotech industry, a higher probability of a successful challenge to a company's patent portfolio could lead to adverse consequences and insolvency for many development-stage biotech companies. This means that changes in regulation could lead to hard-to-predict long-term effects on the complex network of capital investment in the biotech industry. These IP issues are open policy questions that will need to be resolved for follow-on biologics. We discuss some of the trade-offs regarding them later.

\section{How Will The Market Evolve?}

Regulatory environment, technology and manufacturing barriers, and market acceptance and competition will determine market outcomes for follow-on biologics. In our opinion, limited competition of either the nonbranded or the branded variety is most likely in the short run because of regulatory conservatism, relatively high barriers to entry, and initial caution on follow-on product acceptance. For the typical drug, generic prices begin to approach their long-run marginal cost when there are at least ten competitors in the market. ${ }^{23}$ For commercially successful drug products, there has been sufficient entry to drive prices close to marginal costs within a relatively short period after patent expiration, generally less than a year and, more recently, just a few months. The time required likely will be much longer in the follow-on biologic market than in the generic drug market. The basis for this view is explained below, along with a discussion of some changes that could reduce likely regulatory and institutional barriers. ${ }^{24}$

- Regulatory environment. Until Congress changes the PHS Act to create a process for competition in follow-on biologics, prospective entrants will have to do extensive clinical trials under separate Biological Licensing Applications (BLAs). As discussed above, some biologics approved under the FD\&EC Act, such as hGH and recombinant insulin, already have multiple competitors based on NDAs, but entry costs are high, and price competition to date could be limited. Sandoz's suit to direct the FDA to act on its 2003 application for the hGH Omnitrope reflects an alternative third route, through Section 505(b)(2) of the FD\&C Act, which allows the FDA to rely on the published scientific literature or its previous findings for similar products. In June 2006, the FDA approved Sandoz's application but narrowly circum- 


\section{"The recent wave of biologic approvals suggests that there might be limited idle manufacturing capacity in the near future."}

scribed its approval to protein products approved under the FD\&C Act with a single active ingredient, with a well-understood mechanism of action, and that also could be well characterized with existing technology. Furthermore, Omnitrope is not rated as therapeutically equivalent, or substitutable for, other approved human growth hormone products. ${ }^{25}$

Given the rapid growth in spending on biopharmaceuticals and the extensive number of new products likely to be introduced in the coming years, we expect that Congress will act to create some form of an abbreviated process for follow-on biologics. At the same time, given the uncertainty surrounding safety risks, one would expect that Congress will give considerable discretion to the FDA to determine the extent of any clinical testing that will be required for these approvals. In particular, we expect that the scientific criteria for what constitutes a biosimilar product will be left to the discretion of the FDA.

The FDA has been cautious when a new technology poses potential safety hazards. European regulators are ahead of the United States in developing regulations for follow-on biologics, and the European Agency for the Evaluation of Medicinal Products (EMEA) has indicated a case-by-case approach, with some data on clinical efficacy and safety necessary for market approval. To date, two hGH follow-on products to somatropin, Sandoz's Omnitrope and Biopartners' Valtropin, have been approved in Europe. ${ }^{26}$ The FDA could adopt a more restrictive approach than Europe's when incorporating technical guidelines that are applicable to multiple classes of biologics. The recent market withdrawal of two cyclooxygenase-2 (COX-2) inhibitors and the appointment of the special Institute of Medicine Committee to study the impact of FDA procedures on product safety will amplify cautious institutional tendencies on this score. ${ }^{27}$

- Technology and manufacturing barriers. There are also important open issues concerning technology and manufacturing barriers to entry and how rapidly manufacturing costs will decline over time as a result of process innovation.

The recent wave of biologic approvals and expanded pipelines suggests that there might be limited idle manufacturing capacity in the near future. If so, we expect that potential producers of follow-on products would need sizable investments in their own facilities to compete. This would be a major financial hurdle for all but the largest entrants or established generic product manufacturers. The generic product manufacturing industry is undergoing consolidation, but only a few established companies appear capable of undertaking the costs and risks.

Over longer time frames, expansion in manufacturing capacity and technological advances in process engineering could greatly decrease the fixed and variable costs for follow-on biologics. In particular, a new group of follow-on manufactur- 
ing "specialists" might emerge, which might be biotech product firms, manufacturing technology platform firms, or established generic manufacturers (either stand-alone manufacturers or generic arms of diversified large pharmaceutical firms). Expanded roles for outsourced manufacturing specialists could emerge, just as Contract Research Organizations (CROs) have "hollowed out" some aspects of clinical development, if they are able to lower manufacturing costs for biologics.

Competition in process technology could drive down costs, ease market access for new products, raise expected returns to upstream firms, and stimulate entry and innovation. However, these gains might or might not be ultimately passed on to patients. Manufacturers or "integrators" who control IP and market access might capture rents, as suggested by the experience of new entrants, which typically share a larger fraction of profits with manufacturing/marketing partners to bring products to market.

Market acceptance and competition. Market acceptance and competition uncertainties include the substitution rates for existing brand-name biologics and what incentives, reimbursement systems, and marketing expenditures will be needed to encourage rapid substitution.

We expect that users will be cautious with respect to follow-on products in the short term, until clinical experience has accumulated. Some clinical trials will likely be needed to demonstrate that a follow-on product is therapeutically equivalent to the original product. The perspectives of specialist physicians and organized patient groups in therapeutic areas with high usage of biologics will be important in driving or limiting demand for follow-on products.

To overcome barriers to acceptance among physicians and patients, follow-on biologic entrants might find it necessary to establish "reputation bonds" with brand-name products to capture and maintain market share. In this environment, market access is facilitated through specialist education and detailing, as well as through contracts with major health plans and coordination with centralized formulary policies. Relative to generic drugs, companies might have to incur the added costs of professional detailing forces, perhaps comparable to those of specialty drugs and biotech companies (estimated elsewhere at forty people). ${ }^{28}$

\section{The Case Of Combination Hormonal Contraceptives}

In considering how market structure in follow-on biologics could evolve, the case of combination hormonal contraceptives might be instructive. The investment costs and technical complexity of establishing bioequivalence are somewhat higher than for other drugs, and entry has been concentrated in a handful of specialty generic firms. Generic contraceptives are certified by the FDA as bioequivalent to the referenced brand, but they are marketed under separate brand names (that is, as branded generics). There are no more than three generic competitors for even the very largest-selling contraceptive drugs. ${ }^{29}$ As a consequence, generic 
price competition is more limited, relative to other drug classes with comparable market sales.

The barriers to entry can be expected to be greater initially for follow-on biologics than for these hormonal contraceptive products. Hence, we can expect some of the differences observed in this market to be present for follow-on biologics. It is also important to remember that the current rapid pace of generic entry and penetration that now characterizes most drugs with substantial sales when patents expire took many years to evolve. We expect that this also will be true for follow-on biologics.

\section{Discussion And Concluding Comments}

In sum, we expect that regulatory conservatism, high manufacturing barriers to entry, and limited acceptance of follow-on products will constrain the number of market entrants, the key driver of lower generic drug prices. A robust follow-on industry is likely to emerge as regulatory standards evolve and demand develops, but this will probably take time, even for some well-characterized biologics.

Consequently, we believe that conservative assumptions are appropriate in "scoring" the budgetary savings from legislation that creates a regulatory framework for follow-on biologics, even assuming that scientific, public health, and safety issues are resolved. Technological advances and institutional changes eventually will facilitate entry by multiple follow-on manufacturers, but this will take time. In the meantime, prices might drop only moderately, but substantial gains could occur for a small number of entrants with the required skills and assets.

When creating a legal framework for follow-on biologics, however, legislators and regulators should adopt a long-term perspective. Over the coming decades, biopharmaceutical innovation can provide major improvements with respect to the quality and length of human life but could also exacerbate cost pressures and access disparities in health care. It will fall to Congress and the FDA to balance the objectives of innovation incentives and price competition, as was the case when Congress created the Hatch-Waxman program more than two decades ago.

The optimal design of a legal framework for follow-on biologics is beyond the scope of this paper. But given the entrepreneurial character of the biotech industry, we think that it is especially important that Congress carefully consider the intellectual property provisions that will govern competition between innovators and imitators. In particular, Congress will have to consider whether to award market exclusivity to the first follow-on biologic to challenge a patent successfully. If it enacts such a provision, it will also need to determine the data exclusivity period for innovators, because this determines the earliest point in time that followon biologics can enter based on an abbreviated process that relies in whole or part on innovators' safety and efficacy data.

Intellectual property has been an important factor for biotech start-ups in securing venture funding and partnerships with larger firms. Product life cycles for 
new medicines span decades, and R\&D decisions are made with long time horizons on future returns. Legislators might view the encouragement of patent challenges and attendant litigation as a good short-term mechanism for exposing more biologics to follow-on price competition. But increased uncertainty and IP litigation in biotech also would have major negative-incentive effects on capital market decisions for developing private and public biotech firms with promising pipelines. Most of these firms have few if any profitable products.

The European Union (EU) recently instituted a ten-year data-exclusivity period for pharmaceutical innovators. ${ }^{30}$ This prevents patent challengers from filing applications relying on innovators' safety and efficacy data until at least ten years have elapsed. The comparable period in the United States is five years. Given the high costs and long time required to develop a new medicine, five years is generally not sufficient to cover R\&D costs and earn a risk-adjusted return. ${ }^{31} \mathrm{~A}$ longer data-exclusivity period for biologics could be useful for policymakers to consider in their efforts to balance innovation incentives and price competition.

Further investigation and quantitative analysis and simulation would be valuable to policymakers, including the following: modeling the number of market entrants and resulting prices by therapeutic area after follow-on entry; estimating fixed costs of market entry and variable costs of manufacturing, with comparison to generic drugs; identifying likely marketing investments by therapeutic area and their impact on market organization; and estimating long-term effects on R\&D investment and innovation and investment risk in the biotechnology sector.

The authors acknowledge research support for this project from Johnson and Johnson, which had no role in the collection, analysis, and interpretation of data or in the preparation of the manuscript for publication.

\section{NOTES}

1. Gordon Johnson, vice president for regulatory affairs, Generic Pharmaceutical Association, Remarks at FDA/DIA Scientific Workshop on Follow-on Protein Pharmaceuticals, Arlington, Virginia, 16 February 2005.

2. G.J. Mossinghoff, "Overview of the Hatch-Waxman Act and Its Impact on the Drug Development Process," Food and Drug Law Journal 54, no. 2 (1999): 187-194.

3. A third alternative discussed subsequently lies with section 505(b)(2) of the FD\& C Act, which allows the FDA to rely on the published scientific literature or its previous findings for similar products.

4. J.A. DiMasi, R.W. Hansen, and H.G. Grabowski, "The Price of Innovation: New Estimates of Drug Development Costs," Journal of Health Economics 22, no. 2 (2003): 151-185.

5. DiMasi and colleagues' estimates rise to $\$ 897$ million if postapproval costs such as additional clinical testing and the development of new indications are included.

6. J.A. DiMasi and H.G. Grabowski, "R\&D Costs for New Biotech Compounds," Managerial and Decision Economics (forthcoming).

7. The cost data for biological entities cover a later time period and are expected to be higher, given the fact that R\&D costs have been growing faster than general inflation.

8. J.M. Reichert and C. Paquette, "Therapeutic Recombinant Proteins: Trends in U.S. Approvals 1982 to 2002," Current Opinion in Molecular Therapeutics 5, no. 2 (2003): 139-147.

9. T. Oldham, "Working Out the Profit Potential for Follow-On Biologics" (Presentation at IBC conference, Brussels, Belgium, 1-2 March 2005); and E. Schafer, "Opportunities for FOBs in Europe: A Risk Benefit Analysis with EPO" (Presentation at the Institute for International Research Follow-On Biologics Forum, 
Washington, D.C., April 2005). (Schafer's upper bound is $\$ 80$ million, but this assumes two large-scale pivotal trials typically required for a new molecular entity.)

10. H. Grabowski, "Patents and New Product Development in the Pharmaceutical and Biotechnology Industries," Georgetown Public Policy Review 8, no. 2 (2003): 7-24.

11. Data from the FDA electronic Orange Book for active ingredient "somatropin recombinant," http://www .fda.gov/cder/ob/docs/queryai.htm (accessed 7 July 2006).

12. Biotechnology Industry Organization, "A Brief Primer on Manufacturing Therapeutic Proteins," April 2003, http://www.bio.org/healthcare/pmp/factsheetl.asp (accessed 23 May 2006).

13. Grabowski, "Patents and New Product Development."

14. For a recent survey of this literature and an updated analysis, see A. Saha et al., "Generic Competition in the U.S. Pharmaceutical Industry," International Journal of the Economics of Business 13, no. 1 (2006): 15-38.

15. Tufts Center for the Study of Drug Development, "Biotechnology Has Become Vital to Orphan Drug R\&D," Press Release, 22 May 2002, http://csdd.tufts.edu/NewsEvents/RecentNews.asp?newsid=17 (accessed 10 June 2005).

16. Centers for Medicare and Medicaid Services, Health Care Industry Market Update: Pharmaceuticals, 10 January 2003, http://www.cms.hhs.gov/CapMarketUpdates/Downloads/hcimull003.pdf (accessed 7 July 2006).

17. R. Silver, "Wall Street View of the Generic Industry: The Challenges and Opportunities" (Presentation at Generic Drugs Summit, Institute for International Research, Washington, D.C., 27-29 September 2004).

18. J.D. Kleinke, "Re-Naming and Re-Gaming: Medicare's Doomed Attempt to Reform Reimbursement for Injectable Drugs," Health Affairs 23 (2004): w561-w571 (published online 8 December 2004; 10.1377/hlthaff .w4.561).

19. M. Russo and D. Balekdjian, "The Year Payers Stopped Threatening," Pharmaceutical Executive (January 2005): 78-84.

20. H. Grabowski, "Are the Economics of Pharmaceutical Research and Development Changing? Productivity, Patents, and Political Pressures," PharmcoEconomics 22, no. 2 Supp. (2002): 15-24.

21. Only one thirty-month stay is now allowed even if there are multiple patents at issue. P.L. 108-173, modifying sec. 505(j) of the Federal Food, Drug, and Cosmetic Act, 21 U.S. Code, sec. 355(j).

22. Grabowski, "Patents and New Product Development."

23. H. Grabowski, D. Ridley, and K. Schulmann, "Entry and Competition in Generic Biologics," Managerial and Decision Economics (forthcoming).

24. For a more detailed analysis of some alternative scenarios and their characteristics, see the online appendix at http://content.healthaffairs.org/cgi/content/full/25/5/1291/DCl.

25. FDA, "Omnitrope (somatropin [rDNA origin]) Questions and Answers," http://www.fda.gov/cder/drug/ infopage/somatropin/qa.htm (accessed 7 July 2006).

26. "Europe Clears Second Biosimilar Product," PharmaTimes, 5 May 2006.

27. FDA, CDER Report to the Nation: 2004 (sections on drug safety initiative and on recalls), http://www.fda.gov/ cder/reports/rtn/2004/rtn2004-6.HTM (accessed 7 July 2006).

28. K. Cheng, "Predicting Follow-On Biologics Potential: Valuing the Market" (Presentation at Institute for International Research Follow-On Biologics Forum, Washington, D.C., April 2005).

29. Data from the FDA electronic Orange Book for Ortho Tri-Cyclen, Ortho-Novum, and Alesse, http://www .fda.gov.cder/ob/docs/queryai.htm (accessed 7 July 2006).

30. G. Verheugen, "Future Post G-10 Pharmaceutical Strategy," Speech at the Annual Meeting of European Federation of Pharmaceutical Industry and Association, 1 June 2005, http://europa.eu/rapid/pressReleases

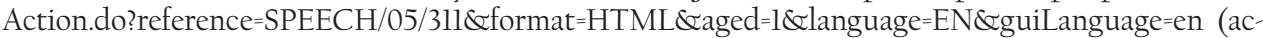
cessed 13 May 2006).

31. Grabowski, "Are the Economics of Pharmaceutical Research and Development Changing?" 